\title{
Phytonutrient Profile of Purple Perilla (Perilla frutescens var. crispa) Seeds
}

\author{
Shiva Ram Bhandari*, Ju Kyong Lee**, and Young-Sang Lee ${ }^{\dagger}$ \\ *Department of Medical Biotechnology, Soonchunhyang University, Asan, 336-745, Republic of Korea \\ ** Department of Applied Plant Sciences, Kangwon National University, Chuncheon, 200-701, Republic of Korea
}

\begin{abstract}
To characterize phytonutrients, the seeds of 12 purple Perilla (Perilla frutescens var. crispa) accessions collected from Korea and Japan were used for quantitative analysis of tocopherols, phytosterols, squalene and fatty acids. The average tocopherol, squalene and phytosterols

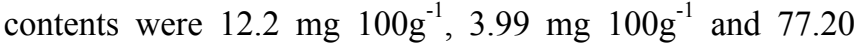
$\mathrm{mg} 100 \mathrm{~g}^{-1}$, respectively. Among 4 tocopherol $(\mathrm{T})$ isomers ( $\alpha-\mathrm{T}, \beta-\mathrm{T}, \gamma-\mathrm{T}$, and $\delta-\mathrm{T}$ ), $\gamma-\mathrm{T}$ was present in the highest quantity $\left(11.03 \mathrm{mg} 100 \mathrm{~g}^{-1}\right)$ with the least variation $(\mathrm{CV}=$ $13.7 \%)$, while $\beta-T$ was present in lowest quantity $(0.25 \mathrm{mg}$ $\left.100 \mathrm{~g}^{-1}\right)$. Compared to campesterol $\left(4.36 \mathrm{mg} 100 \mathrm{~g}^{-1}\right)$ and stigmasterol (13.32 mg $\left.100 \mathrm{~g}^{-1}\right)$, $\beta$-sitosterol exhibited higher quantity $\left(59.51 \mathrm{mg} 100 \mathrm{~g}^{-1}\right)$ with $9.5 \%$ of variation. The major fatty acids were unsaturated fatty acids such as linolenic $(61.5 \%)$, linoleic (17.3\%), and oleic (9.9\%) acids compared to saturated ones: palmitic (7.6\%) and stearic (3.7\%) acids. When Korean and Japanese accession were compared, almost no difference in content could be observed, while more variation as evaluated by $\mathrm{CV}$ (\%) could be observed in Japanese accession in most phytonutrients suggesting wider genetic variation of purple Perilla in Japan. Presence of all above-mentioned phytonutrient compounds strongly suggested health beneficial value of purple Perilla seeds.
\end{abstract}

Keywords : Perilla frutescens var. crispa, purple Perilla, fatty acid, tocopherols, phytosterols, squalene

Perilla frutescens (L.) Britt, a member of family Lamiaceae, is an autogamous annual species which is widely cultivated in Asian countries like China, S. Korea, Nepal and Japan since the ancient times (Nitta and Ohnishi, 1999). Recently, it has been also grown in to USA, Europe and Russia (Nitta et al., 2003). The species consists of two varieties that can be identified based upon their morphology and uses; $P$. frutescens var. frutescens, a seed oil crop and $P$. frutescens var. crispa, a leafy vegetable crop (Lee et al., 2002). The later is commonly called as 'Cha-jo-ki' in Korean name, or purple Perilla due to the color of their leaves. Purple Perilla also has been used as a traditional herbal medicine; e.g., the leaves as well as seeds were used for colds and coughs and for the promotion of digestion. Perilla seed, a rich source of protein (17\%) and fat (51\%) has long been used as plant oil source in various oriental countries including Korea, China, Japan, and India (Adhikari et al., 2006) as a delicacy after frying or in combination with cereals or vegetables after cooking and also as a cooking medium (Longvah \& Deosthale, 1991).

Perilla fresh leaves has also been used as condiments or flavoring agents in various Korean foods (Shin \& Kim, 1994). Similarly polysaccharides isolated from leaves exhibited stimulatory effects on the macrophage system (Kwon et al., 2002). Among different kinds of vegetable oil, Perilla seed oil contains the highest amount of $n-3$ fatty acid (a -linolenic acid, C18:3) (Longvah \& Deosthale, 1991), which is known to improve the learning ability, retinal function, suppression of carcinogenesis, metastasis, thrombosis and allergy (Kinsella, 1991). Beside a-linolenic acid, the oil also contains the fatty acids like palmitic acid (C16:0), stearic acid (C18:0), oleic acid (C18:1) and linoleic acid (C18:2). The Perilla seeds also contain various groups of lipid nutraceutical compounds. The first group could be tocopherol, a lipid soluble vitamin $\mathrm{E}$ which has the antioxidant properties and play an important role in human and animal nutrition (Ohkatsu et al., 2001). The second group could be phytosterols which are mainly known for cholesterollowering effect (Jones et al., 1997) and preventive effect on the development of colon cancer (Awad and Fink, 2000; Janezic and Rao, 1992). $\beta$-sitosterol, a major form

${ }^{\dagger}$ Corresponding author: (Phone) +82-41-530-1287 (E-mail) mariolee@sch.ac.kr

$<$ Received 10 June 2011; Revised 13 June 2011; Accepted 16 June 2011> 
of phytosterol decreases the number of developed tumors in the colon (Raicht et al., 1980), shows stimulatory effect on the epithelial cell proliferation (Janezic and Rao, 1992), and inhibits human cancer cell growth during incubation (Awad et al., 1998). Another phytosterol, stigmasterol was reported to bind to chondrocyte membrane and possesses potential anti-inflammatory and anti-catabolic properties (Gabay et al., 2010). The third group of lipid phytonutrient of purple Perilla seeds could be squalene, a kind of hydrocarbon strongly involved in the biosynthesis of cholesterol (Moreda and Perez-Camino, 2001) and exhibits protective activity against several carcinogens like azoxymethane (Rao et al., 1998).

However, information on quantitative properties of abovementioned lipid phytonutrients in Perilla crop, especially in purple Perilla are very limited and this study was conducted to quantify the contents of tocopherols, phytosterols, squalene and fatty acid composition of 12 purple Perilla accession collected from Korea and Japan.

\section{MATERIALS AND METHODS}

\section{Plant materials}

Twelve accessions of purple Perilla (Perilla frutescens var. crispa) seeds were collected from Korea and Japan. Among them, the seeds of Korean accessions were collected in such habitats as roadsides, wastelands, abandoned fields, and the marginal lands around farmlands, because var. crispa is not being cultivated due to the decreasing use of its seeds in Chinese medicine. It is occasionally found in a relict form in Korea (Lee and Ohnishi, 2001). While, the seeds of Japanese accessions were kindly provided from the Plant Germplasm Institute, Graduate School of Agriculture, Kyoto University, Japan. In Japan, var. crispa is extensively cultivated and used as a vegetable crop. To propagate the seeds of the twelve accessions of var. crispa, five individuals of each accession were grown in a field at the Faculty of Agriculture, Kangwon National University, Chuncheon, Gangwon Province. The 12 accessions of var. crispa from Korea and Japan are small in seed size $(<2 \mathrm{~mm})$, have only hard seeds with a dark brown color, have purple leaves and stem, have either wrinkly or non-wrinkly leaves. The seeds were ground to fine powder and stored at $-20^{\circ} \mathrm{C}$ for further analysis.

\section{Tocopherols, phytosterols and squalene analysis}

The samples for the analysis of tocopherols, phytosterols and squalene were prepared according to Park et al. (2004) with some modifications. Dry powdered Perilla seeds (1.5 g) were extracted on $10 \mathrm{~mL}$ ethanol with ascorbic acid as an antioxidant. The mixture was shaked on hot water bath $\left(80^{\circ} \mathrm{C}\right.$ ) for 10 minutes. After that $300 \mu \mathrm{L}$ of $44 \%$ potassium hydroxide was added and shaked for 18 minutes on same conditions for saponification. After cooling on ice, $10 \mathrm{~mL}$ of n-hexane and $10 \mathrm{~mL}$ of distilled water was added and the solution was centrifuged, then upper hexane layer was collected and again added the $10 \mathrm{ml} \mathrm{n}$-hexane to the remaining solution. The process was repeated for three times and collected hexane solution was then washed by $10 \mathrm{ml}$ of distilled water for three times. The solution was passed through $\mathrm{Na}_{2} \mathrm{SO}_{4}$ anhydrous to remove the water, concentrated on rotary evaporator and dissolved on isooctane. The samples were analyzed by gas chromatography (Agilent 6890, Agilent technologies Co. USA) under optimized conditions by flame ionization detector (FID). The analysis was performed on a capillary column $(25.0 \mathrm{~m} \times 250 \mu \mathrm{m} \times 0.40$ $\mu \mathrm{m}$ nominal) of CP-SIL $8 \mathrm{CB}$ capillary on constant column flow $\left(1.0 \mathrm{~mL} \cdot \mathrm{min}^{-1}\right)$. Similarly injection volume was $1 \mu \mathrm{L}$ with split ratio $1: 50$. The temperature was set at $290^{\circ} \mathrm{C}$ for both injector and detector with carrier gas He. The column oven temperature was initially set on $220^{\circ} \mathrm{C}$ for 2 minutes, then raised up to $290^{\circ} \mathrm{C}$ at the rate of $5^{\circ} \mathrm{C} \mathrm{min}{ }^{-1}$ and held for 14 minutes, then, the temperature was raised to $310^{\circ} \mathrm{C}$ at $10^{\circ} \mathrm{C} \mathrm{m^{-1 }}$ and held for 18 minutes. Peak identifications were conducted based upon the retention times of standard compounds.

\section{Fatty acid composition analysis}

Sample preparation and fatty acids composition in Perilla seeds were performed according to Kim et al. (2000). Powdered Perilla seeds $(0.5 \mathrm{~g})$ were methylated with $680 \mu \mathrm{L}$ methylation mixture (Methanol: benzene: 2,2-dimethoxypropane: sulfuric acid $=39: 20: 5: 2$ ) and $400 \mu \mathrm{L}$ heptanes. After heating for 2 hours at $80^{\circ} \mathrm{C}$ in water bath and cooling on room temperature, the samples were centrifuged for 2 minutes at $2000 \mathrm{rpm}$ and upper heptanes layer was collected. The 
samples were then subjected to gas chromatography (Varian, CP-3800) using a CP-SIL- 88 CB FAME $(50.0 \mathrm{~m} \times 0.25$ $\mathrm{mm} \times 0.2 \mu \mathrm{m}$ nominal) capillary column. The temperature for injector and detector (FID; flame ionization detection) were set on 210 and $290^{\circ} \mathrm{C}$, respectively and the carrier gas was helium. The injection volume was $1 \mu \mathrm{L}$ with split ratio $1: 50$ on constant column flow $\left(1.0 \mathrm{~mL} \cdot \mathrm{min}^{-1}\right)$. The oven temperature was initially set on $100^{\circ} \mathrm{C}$ for 5 minutes, then raised up to $160{ }^{\circ} \mathrm{C}$ at $5^{\circ} \mathrm{C} \min ^{-1}$ and held for 5 minutes, again raised up to $180^{\circ} \mathrm{C}$ at $4{ }^{\circ} \mathrm{C} \min ^{-1}$ and held for 10 minutes and then it was raised up to $220^{\circ} \mathrm{C}$ at $3{ }^{\circ} \mathrm{C}$ $\min ^{-1}$ and held for 15 minutes. Authentic standards were used to identify the peaks based upon the retention time.

\section{Chemicals and reagents}

Vitamin E standards (tocopherols: $a-T, \beta-T, \gamma-T$, and $\delta$ -T) were obtained from Merck (Darmstadt, Germany). Squalene, stigmasterol, $\beta$ - sitosterol and campesterol were purchased from Sigma-Aldrich (St. Louis, MO, USA). Ascorbic acid, chloroform and anhydrous sodium sulfate were obtained from Samchun (Seoul, Republic of Korea), potassium hydroxide, benzene, sulfuric acid and n-heptanes were purchased from Daejung (Seoul, Republic of Korea) and ethanol was purchased from Duksan chemicals (Seoul, Republic of Korea). Fatty acid methylation mixture was purchased from Supleco (USA).

\section{RESULTS AND DISCUSSION}

\section{Vitamin E content}

Vitamin E contents of the different accession of Korean and Japanese purple Perilla seeds are presented in Table 1. Only tocopherol form of vitamin $\mathrm{E}$ : $a-\mathrm{T}, \beta-\mathrm{T}, \gamma-\mathrm{T}$, and $\delta$ -T were observed in the Perilla seeds, while no tocotrienols were observed as reported by Lee and Kim (2008). The minimum, maximum, and average total vitamin $\mathrm{E}$ contents of 12 tested accessions were 9.36, 13.70, and $12.20 \mathrm{mg}$ $100 \mathrm{~g}^{-1}$, respectively. Total tocopherol content in Korean accession seeds ranged from $12.76 \mathrm{mg} 100 \mathrm{~g}^{-1}$ (K126157) to $13.70 \mathrm{mg} 100 \mathrm{~g}^{-1}$ (K126205) with an average of 13.25

Table 1. Seed tocopherol contents of purple Perilla accessions collected from Korea and Japan.

\begin{tabular}{|c|c|c|c|c|c|c|}
\hline \multirow{2}{*}{ Collection } & \multirow{2}{*}{ ACC.Number } & \multicolumn{5}{|c|}{ Tocopherol (T) content (mg 100g $\left.\mathrm{g}^{-1}\right)$} \\
\hline & & $a-T$ & $\beta-\mathrm{T}$ & $\gamma-\mathrm{T}$ & $\delta-\mathrm{T}$ & Total \\
\hline \multirow{7}{*}{ Korea } & K126157 & 0.51 & 0.20 & 11.65 & 0.40 & 12.76 \\
\hline & K126158 & 0.49 & 0.26 & 12.35 & 0.44 & 13.53 \\
\hline & K126177 & 0.45 & 0.26 & 11.67 & 0.45 & 12.82 \\
\hline & K126203 & 0.59 & 0.25 & 12.14 & 0.45 & 13.44 \\
\hline & K126205 & 0.49 & 0.29 & 12.46 & 0.46 & 13.70 \\
\hline & Mean & 0.51 & 0.25 & 12.05 & 0.44 & 13.25 \\
\hline & $\mathrm{CV}(\%)$ & 10.6 & 13.6 & 3.1 & 5.4 & 3.2 \\
\hline \multirow{9}{*}{ Japan } & K126334 & 0.41 & 0.21 & 8.32 & 0.42 & 9.36 \\
\hline & K126335 & 0.39 & 0.21 & 8.34 & 0.43 & 9.37 \\
\hline & K126336 & 0.45 & 0.24 & 12.07 & 0.68 & 13.44 \\
\hline & K126337 & 0.34 & 0.17 & 11.33 & 0.40 & 12.24 \\
\hline & K126355 & 0.42 & 0.28 & 11.04 & 0.47 & 12.21 \\
\hline & K126357 & 0.38 & 0.32 & 9.23 & 0.52 & 10.45 \\
\hline & K015970 & 0.54 & 0.34 & 11.72 & 0.47 & 13.08 \\
\hline & Mean & 0.42 & 0.25 & 10.29 & 0.48 & 11.45 \\
\hline & CV (\%) & 15.5 & 25.0 & 15.7 & 20.0 & 14.9 \\
\hline \multirow{2}{*}{ Total } & Mean & 0.45 & 0.25 & 11.03 & 0.47 & 12.20 \\
\hline & CV (\%) & 16.1 & 20.3 & 13.7 & 16.3 & 13.0 \\
\hline
\end{tabular}


$\mathrm{mg} 100 \mathrm{~g}^{-1}$ and $3.2 \% \mathrm{CV}$, while Japanese accession seeds exhibited total tocopherol contents ranging from $9.36 \mathrm{mg}$

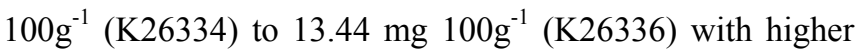
coefficient of variation (14.9\%). Among the four tocopherols, $\beta-\mathrm{T}$ was present in least quantity $\left(0.25 \mathrm{mg} 100 \mathrm{~g}^{-1}\right)$ but had highest variations $(20.3 \%)$ while $\gamma$-T was present as highest quantity (11.03 mg $\left.100 \mathrm{~g}^{-1}\right)$ in all accessions as reported earlier by Shin and Kim (1994) and Park et al. (2004) who reported $\gamma-T$ as a major form of vitamin $E$ in purple Perilla.

\section{Squalene content}

The squalene content tested in different accessions of purple Perilla seeds is presented in Table 2. The average squalene content was $3.99 \mathrm{mg} 100 \mathrm{~g}^{-1}$, which is higher than various seeds and fruits reported by Ryan et al. (2007). The lowest squalene content $\left(2.52 \mathrm{mg} 100 \mathrm{~g}^{-1}\right)$ was observed in Japanese accession (K126337), while the highest squalene content (5.68 mg $100 \mathrm{~g}^{-1}$ ) was observed in Korean accession (K126158). Considering the fact that K126205, an accession which showed lowest $\left(4.06 \mathrm{mg} 100 \mathrm{~g}^{-1}\right)$ squalene content among Korean accessions exhibited similar squalene content compared to K126355 which showed highest value (4.19 mg $100 \mathrm{~g}^{-1}$ ) among Japanese purple Perilla accessions suggested that purple Perilla found in Korea may have higher squalene compared to those cultivated in Japan. Also accessions collected in Japan showed higher variation $(\mathrm{CV}=18.6 \%)$ than Korean accessions $(\mathrm{CV}=14.2 \%)$.

\section{Phytosterols content}

Three major phytosterols: campesterol, sitosterol, and stigmasterol in purple Perilla seeds were quantified. The total phytosterol content in 5 tested Korean accessions ranged from $76.48 \mathrm{mg} 100 \mathrm{~g}^{-1}$ to $84.91 \mathrm{mg} 100 \mathrm{~g}^{-1}$ with an average of $81.23 \mathrm{mg} 100 \mathrm{~g}^{-1}$ (Table 2), while total phytosterol contents in tested 7 Japanese purple Perilla seeds varied from $63.17 \mathrm{mg} 100 \mathrm{~g}^{-1}$ to $80.97 \mathrm{mg} 100 \mathrm{~g}^{-1}$ with an average of $74.32 \mathrm{mg} 100 \mathrm{~g}^{-1}$. Similar to the case of vitamin $\mathrm{E}$ and squalene, higher variations as evaluated by $\mathrm{CV}(\%)$ could be observed in Japanese accessions (8.3\%) compared to

Table 2. Seed squalene and phytosterol contents of purple Perilla accessions collected from Korea and Japan.

\begin{tabular}{|c|c|c|c|c|c|c|}
\hline \multirow{2}{*}{ Collection } & \multirow{2}{*}{ ACC.Number } & \multirow{2}{*}{$\begin{array}{l}\text { Squalene } \\
\left(\mathrm{mg} 100 \mathrm{~g}^{-1}\right)\end{array}$} & \multicolumn{4}{|c|}{ Phytosterol content $\left(\mathrm{mg} 100 \mathrm{~g}^{-1}\right)$} \\
\hline & & & Campesterol & Stigmasterol & $\beta$-sitosterol & Total \\
\hline \multirow{7}{*}{ Korea } & K126157 & 4.86 & 4.98 & 11.31 & 61.64 & 77.93 \\
\hline & K126158 & 5.68 & 4.13 & 15.05 & 65.73 & 84.91 \\
\hline & K126177 & 4.34 & 3.66 & 12.17 & 60.65 & 76.48 \\
\hline & K126203 & 5.43 & 4.06 & 12.76 & 67.70 & 84.52 \\
\hline & K126205 & 4.06 & 3.76 & 13.30 & 65.25 & 82.31 \\
\hline & Mean & 4.87 & 4.12 & 12.92 & 64.20 & 81.23 \\
\hline & $\mathrm{CV}(\%)$ & 14.2 & 12.6 & 10.8 & 4.6 & 4.7 \\
\hline \multirow{9}{*}{ Japan } & K126334 & 3.90 & 4.52 & 13.82 & 56.80 & 75.14 \\
\hline & K126335 & 3.12 & 3.98 & 11.55 & 47.64 & 63.17 \\
\hline & K126336 & 3.81 & 5.30 & 14.98 & 60.41 & 80.69 \\
\hline & K126337 & 2.52 & 4.19 & 14.83 & 53.05 & 72.07 \\
\hline & K126355 & 4.19 & 4.51 & 15.67 & 56.59 & 76.77 \\
\hline & K126357 & 3.23 & 4.97 & 14.33 & 61.67 & 80.97 \\
\hline & K015970 & 2.74 & 4.29 & 10.11 & 57.03 & 71.43 \\
\hline & Mean & 3.36 & 4.54 & 13.61 & 56.17 & 74.32 \\
\hline & CV (\%) & 18.6 & 10.1 & 14.9 & 8.4 & 8.3 \\
\hline \multirow{2}{*}{ Total } & Mean & 3.99 & 4.36 & 13.32 & 59.51 & 77.20 \\
\hline & CV (\%) & 25.0 & 11.7 & 13.2 & 9.5 & 8.1 \\
\hline
\end{tabular}


Table 3. Seed fatty acid composition of purple Perilla accessions collected from Korea and Japan.

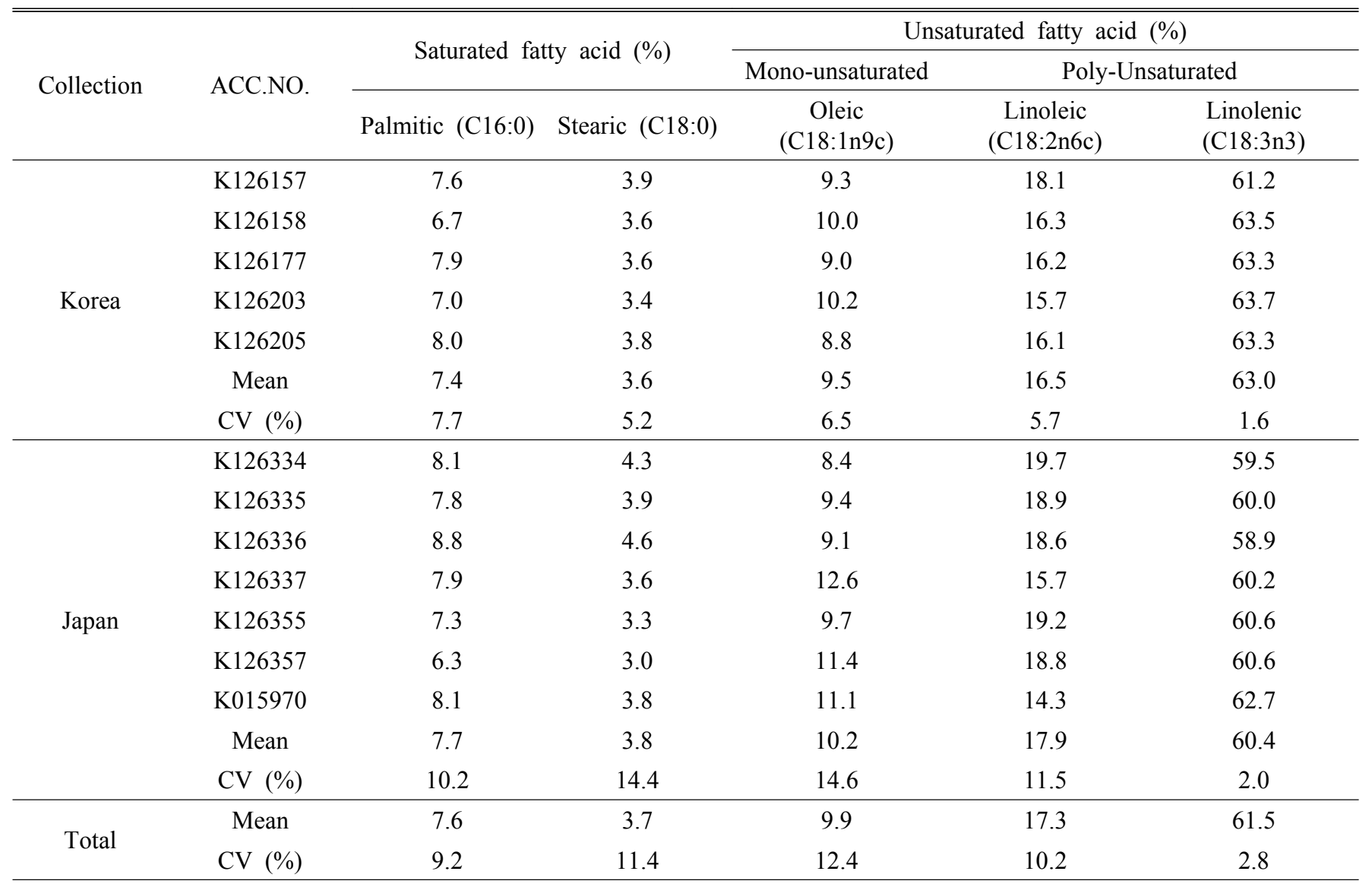

Korean ones (4.7\%). In both Korean and Japanese accessions major form of phytosterol in purple Perilla seed was $\beta$ -sitosterol (average $59.51 \mathrm{mg} 100 \mathrm{~g}^{-1}$ ) compared to stigmasterol

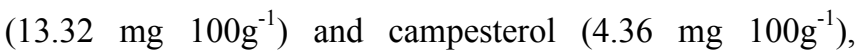
which was similar to previous studies (Weihrauch and Gardner, 1978; Normen et al., 1999; Ryan et al., 2007) that reported $\beta$-sitosterol as a major form of phytosterol.

\section{Fatty acid composition}

Among 37 tested fatty acids, five fatty acids could be detected under our experimental conditions and a-linolenic (C18:3n3) acid exhibited highest (61.5\%) composition as reported earlier (Shin \& Kim, 1994; Longvah et al., 2000; Siriamornpun et al., 2006) in all tested accessions (Table $3)$. The other fatty acids were palmitic (C16:0), stearic (C18:0), oleic $(\mathrm{C} 18: 1 \mathrm{n} 9 \mathrm{c})$ and linoleic $(\mathrm{C} 18: 2 \mathrm{n} 6 \mathrm{c})$ acids which showed $7.6 \%, 3.7 \%, 9.9 \%$ and $17.3 \%$ of total fatty acids, respectively. The composition of saturated fatty acids (palmitic and stearic acid) ranged from 9.3\% to $13.4 \%$, while mono- and poly-unsaturated fatty acids (oleic, linoleic and linolenic acid) were the major form consisting almost $90 \%$ of total fatty acids. Such high presence of unsaturated fatty acids in purple Perilla seeds suggested higher health beneficial effects since these fatty acids may decrease the blood cholesterol levels (Hargrove et al., 2001).

All above mentioned results regarding the presence of various phytonutrients in purple Perilla seeds suggested health beneficial effects of purple Perilla, especially when consumed in form of plant oil.

\section{REFERENCES}

Adhikari, P., K. T. Hwang, J. N. Park, and C. K. Kim. 2006. Policosanol content and composition in Perilla seeds. J. Agric. Food Chem. 54 : 5359-5362.

Awad, A. B. and C. S. Fink. 2000. Phytosterols as anticancer dietary components: Evidence and mechanism of action. 
JN. $130: 2127-2130$.

Awad, A. B., R. L. Von Holtz, J. P. Cone, C. S. Fink, and Y. C. Chen. 1998. Beta sitosterol inhibits growth of HT-29 human colon cancer cells by activating the sphingomyelin cycle. Anticancer Res. 18 : 471-473.

Gabay, O., C. Sanchez, C. Salvat, F. Chevy, M. Breton, G. Nourissat, C. Wolf, C. Jacques, and F. Berenbaum. 2010. Stigmasterol: a phytosterol with potential anti-osteoarthritic properties. Osteoarthritis Cartilage. 18 : 106-116.

Hargrove, R. L., T. D. Etherton, T. A. Pearson, E. H. Harrison, and P. M. Kris-Etherton. 2001. Low-fat and high-monounsaturated fat diets decrease human low-density lipoprotein oxidative susceptibility in vitro. JN. $131: 1758-1763$.

Janezic, S. A. and A. V. Rao. 1992. Dose-dependent effects of dietary phytosterol on epithelial cell proliferation of the murine colon. Food Chem. Toxicol. 30 : 611-616.

Jones, P. J., D. E. Macdougall, F. Ntanios, and C.A. Vanstone. 1997. Dietary phytosterols as cholesterol-lowering agents in humans. Can. J. Physiol. Pharmacol. 75 : 217-227.

Kim, J. K., N. H. Kim, J. K. Bang, B. K. Lee, C. B. Park, and B. H. Lee. 2000. Fatty acid composition analysis of major oil crops by one-step extraction/methylation method. Korean J. Crop Sci. 45 : 211-215.

Kinsella, I. E. 1991. a-linolenic acid: functions and effects on linoleic acid metabolism and eicosanoid mediated reactions. Adv. Food Nutr. Res. 35 : 1-184.

Kwon, K. H., K. I. Kim, W. J. Jun, D. H. Shin, H. Y. Cho, and B. S. Hong. 2002. In vitro and in vivo effects of macrophagestimulatory polysachharide from leaves of Perilla frutescens var. crispa. Biol. Pharm. Bull. 25 : 367-371.

Lee, J.K. and O. Ohnishi. 2001. Geographic differentiation of morphological characters among Perilla crops and their weedy types in East Asia. Breed. Sci. 51 : 247-255.

Lee, J. K., M. Nitta, N. S. Kim, C. H. Park, K. M. Yoon, Y. B. Shin, and O. Ohnishi. 2002. Genetic diversity of Perilla and related weedy types in Korea determined by AFLP analyses. Crop Sci. 42 : 2161-2166.

Lee, Y. S. and M. K. Kim. 2008. Absence of tocotrienol form of vit $\mathrm{E}$ in purple Perilla (Perilla frutescens var. acuta Kudo) seeds confirmed by comparative analysis using HPLC and GC. Korean J. Crop Sci. 53 : 115-120.

Longvah, T. and Y. G. Deosthale. 1991. Chemical and Nutritional studies on Hanshi (Perilla frutescens), a traditional oil seed from Northeast India. JAOCS. 68 : 781.

Longvah, T., Y. G. Deosthale, P., and U. Kumar. 2000. Nutritional and short term toxicological evaluation of Perilla seed oil. Food Chem. 70 : 13-16.

Moreda, W., M. C. Perez-Camino, and A. Cert. 2001. Gas and liquid chromatography of hydrocarbons in edible vegetable oils. J. Chrom. A. 936 : 159-171.

Nitta, M. and O. Ohnishi. 1999. Genetic relationships among two Perilla crops, shiso and egoma, and the weedy type revealed by RAPD markers. Genes Genet. Syst. 74 : 43-48.

Nitta, M., J. K. Lee, and O. Ohnishi. 2003. Asian Perilla crops and their weedy forms: their cultivation, utilization and genetic relationships. Econ. Bot. 57 : 245-253.

Normen, L., M. Johnsson, H. Adersson, Y. Van Gameren, and P. Dutta. 1999. Plant sterols in vegetables and fruits commonly consumed in Sweden. Eur. J. Nutr. 38 : 84-89.

Ohkatsu, Y., T. Kajiyama, and Y. Arari. 2001. Antioxidant activities of tocopherols. Polym. Degrad. Stab. 72 : 303-311.

Park, K. Y., C. S. Kang, Y. S. Lee, Y. H. Lee, and Y. S. Lee. 2004. Tocotrienol and tocopherol content in various plant seeds. Korean J. Crop Sci. 49 : 207-210.

Raicht, R. F., B. I. Cohen, E. P. Fazzini, A. N. Sarwal, and M. Takahashi. 1980. Protective effect of phytosterols against chemically induced colon tumors in rats. Cancer Res. 40 : 403-405.

Rao, C. V., H. L. Newmark, and B. S. Reddy. 1998. Chemopreventive effect of squalene on colon cancer. Carcinogenesis. 19 : 287-290.

Ryan, E., K. Galvin, T. P. O'Connor, and A. R. Maguire. 2007. Phytosterol, Squalene, Tocopherol Content and Fatty Acid Profile of Selected Seeds, Grains, and Legumes. Plant Foods Hu. Nutr. 62 : 85-91.

Shin, H. S. and S. W. Kim. 1994. Lipid composition of Perilla seeds. JAOCS. $71: 619$.

Siriamornpun, S., D. Li, L. Yang, S. Suttajit, and M. Suttajit. 2006. Variation of lipid and fatty acid compositions in Thai Perilla seeds grown at different locations. Songklanakarin J. Sci. Technol. $28: 17-21$.

Weihrauch, J.L, and J. M. Gardner. 1978. Sterol content of foods of plant origin. J. Am. Diet. Assoc. 73 : 39-47. 